\title{
A multi objective optimization of gear cutting in WEDM of Inconel 718 using TOPSIS method
}

\author{
K.D. Mohapatra ${ }^{\mathrm{a}^{*}}$ and S.K. Sahoo ${ }^{\mathrm{a}}$
}

${ }^{a}$ Department of Mechanical Engineering, National Institute of Technology, Rourkela, India

\begin{tabular}{l}
\hline C H R O N I C L E \\
\hline Article history: \\
Received January 16, 2017 \\
Received in revised format: \\
May 22, 2017 \\
Accepted May 28, 2017 \\
Available online \\
May 28, 2017 \\
\hline Keywords: \\
Addendum \\
Dedendum \\
Gear \\
Kerf \\
Material removal rate \\
Spark
\end{tabular}

\begin{abstract}
A B S T R A C T
The present paper deals with the experimental analysis and multi objective optimization of gear cutting process of Inconel 718 using WEDM. The objective of the present work is to optimize the parameters in order to maximize the material removal rate and minimize the kerf in a gear cutting process to get the optimum value. The MRR and kerf play a major role in optimizing the parameters in WEDM process. The experiment is carried out in the wire EDM machine using brass wire as the electrode, Inconel 718 as the work-piece material and distilled water as the dielectric. The design array is created by using Design of Experiment in a Taguchi L16 orthogonal array repeated once. The gear has a base diameter of $20 \mathrm{~mm}$, addendum diameter of $22.5 \mathrm{~mm}$ and a pressure angle of $20^{\circ}$ with 16 numbers of teeth. The machining operation is carried out by taking 3 input parameters at 4 different levels each. The output parameters such as Material Removal rate and Kerf width were obtained and optimized using TOPSIS method to know the optimum setting. Microstructural analysis of both material and wire were studied to know the various defects during the machining operation. Various plots were obtained to know the effects of the process parameters in WEDM. A regression model was also obtained to validate the statistical model values with the experimental. ANOVA table and Response table were carried out to know the significant parameters and rank respectively in the Wire EDM process. Surface roughness, Addendum and Tooth width of gears were also found out at the optimum settings. The optimum setting of the gear obtained can be used to produce high quality gears and can also be applied for future findings.
\end{abstract}

\section{Introduction}

Wire EDM is an unconventional machining operation process that uses spark erosion process for the removal of material from the material piece, where the electrical sparks are developed between the material piece and the tool wire electrode. The wire and the work-piece is flushed in the dielectric fluid is such a way that the work-piece does not touch the wire. The sparks generated evaporate minute amount of work-piece material which are then ejected and washed away by the dielectric fluid. Now WEDM is a vast technique in a high precision machining of all types of conductive materials like

* Corresponding author.

E-mail address: kitu.kasinath1@gmail.com (K.D. Mohapatra)

(C) 2018 Growing Science Ltd. All rights reserved. doi: $10.5267 /$ j.ds1.2017.6.002 
graphite, metals and metallic alloys. In WEDM the vibration and movement of the wire electrode is one of the most important phenomena in the machining process. The decrease of the wire deflection and vibration is one of the most important criteria in attaining high shape accuracy and efficient machining.

When the spark melts, a small portion of the melted material is removed and is washed away. The left over material re-freezes to form a layer over the surface called as the recast layer. The layer contains micro cracks, micro structure, impurities, tensile stress and other undesirable features when put to use. Different WEDM machining parameters are used while cutting operations and they can be varied within a certain range. The wire is provided with an upper and lower water nozzle in such a way that the water comes out uniformly between both the guides. As fresher and more striking materials were developed and more complex shapes were generated, the conventional machining operations will reach their limitations and the wire EDM use will be increased in manufacturing and will endure to grow at a faster rate. Gears are the most important elements used in machinery. The output of the gear depends on manufacturing and accuracy of its design. So the precise manufacturing in a gear needs design considerations and number of calculations. Gear cutting by wire EDM is one of the most important phenomena in this operation. Many gears are of complex shapes and sizes that are difficult to machine by other nonconventional operations can be easily machined by wire EDM machine. Gears find its applications in many industries, truck brakes, rotors, pumps, clock, aerospace etc. In WEDM these gears can be easily cut with required numbers of teeth. Many Inconel gears also find its applications in turbo machining industry, automotive markets, tooling and medical prototypes.

\section{Literature Review}

Several experiments have been carried out in the field of WEDM machining operations and many new discoveries on the WEDM are still going on. Some of the contributions made in the analysis and investigation regarding this field are listed. Habib and Okada (2016) studied the movement of the wire electrode during fine WEDM process. The modelling and optimization of Nimonic C-263 super alloy was carried out by Taylor et al. (2015) using multi cut strategy in wire EDM. They found that the multicut strategy improves the surface roughness and also minimizes the thickness of the recast layer of the job. Rajurkar and Wang (1993) studied the online monitoring of wire EDM. They determined the relationship between the surface finish and the machining rate under optimal machine settings. A proposed model to estimate the thermal load on wire EDM electrode was developed by Banerjee et al. (1993). Speeding and Wang (1997) studied the modeling of wire EDM process. They developed two models and compared for goodness of fit. They conclude that both the models give accurate results for the process. Mohapatra and Sahoo (2015a, 2015b) studied the microstructural analysis and optimization in gear cutting process for AISI 304 stainless steel using wire EDM. They further studied the wire EDM parameters for gear cutting process using Desirability with PCA. Mohapatra and Sahoo (2014) optimized the parameters in wire EDM process for gear cutting. They optimized the WEDM parameters using Taguchi quality Loss function. Li et al. (2014) studied the machining characteristics of Inconel 718 by Sinking EDM and wire EDM. They found that the major contribution factor of Inconel-718 was high toughness due to the absence of micro-cracks on the EDMed surface. The micro rotating structure using micro wire EDM was studied by Geng et al. (2014). Zhang et al. (2014) developed a macroscopic mechanical model of wire electrode deflection considering temperature increment in MS WEDM Process. Kumar et al. (2014) studied the microstructural analysis and tool wear surface of pure titanium in wire Electric discharge machining process. They found rupturing and wear in the wire due to high values of spark frequency and peak current. The effect of process parameters on Material removal rate in WEDM was investigated by Singh and Garg (2009). They concluded that the Material Removal Rate increases with the increase in Pulse on time and Peak current. Subhramanyam and Sarkar (2013) studied the statistical analysis of WEDM on surface finish. Sharma et al. (2016) studied the effect of wire diameter on surface integrity of Inconel 706 for gas turbine applications in wire electric discharge machine. 
From the past literature it is seen that very few works have been contributed to the field of gear cutting by wire EDM process. Very less work has also been carried out on machining of Inconel material in a gear cutting process. So the present work focuses on cutting of the gear and to optimize it in order to produce high quality gears with better accuracy in the gears and its teeth.

\section{Experimental Work}

\subsection{Material selection, Parameter selection and Specifications}

The following experiment is performed in ELECTRONICA Ecocut ELPULS 15 machine. The material selection is one of the important criteria in wire EDM process. Inconel 718 is taken as the base material for the gear cutting process. Brass wire $(0.25 \mathrm{~mm})$ is taken as the tool electrode for the experimentation. The dielectric fluid used for the experiment is distilled water. The parameter selection is one of the most important criteria in WEDM process. The ranges have to select in such a way that they are within the machine constraints. From the past literatures and experimentation on WEDM it is seen that there are more chances of wire breakage by taking the parameters closest to the highest and the lowest range. So the material should be chosen carefully in order to carry out the experimentation. Three process parameters such as Pulse on time $\left(\mathrm{T}_{\mathrm{ON}}\right)$, Pulse off time $\left(\mathrm{T}_{\mathrm{OFF}}\right)$ and Wire Tension $\left(\mathrm{W}_{\mathrm{T}}\right)$ were taken and varied at 4 different levels. Table 1 depicts the machine parameters used for the experiment. The specification of machine and fixed parameters is shown in Table 2. Table 3 shows the compositions of the tool and work-piece material used for the experiment.

Table 1

Machine parameters used in the experimentation

\begin{tabular}{llllll}
\hline Parameters/Levels & Units & I & II & III & IV \\
\hline Pulse on time & $\mu \mathrm{s}$ & 110 & 113 & 116 & 119 \\
Pulse off time & $\mu \mathrm{s}$ & 50 & 53 & 55 & 57 \\
Wire Tension & Kg-f & 4 & 5 & 6 & 7 \\
\hline
\end{tabular}

Table 2

Machine specifications and constant parameters

\begin{tabular}{llll}
\hline Machine specifications & Values & Constant Parameters & Values \\
\hline $\mathbf{X} * Y$ & $250 \mathrm{~mm} * 350 \mathrm{~mm}$ & Wire feed rate $\left(\mathrm{W}_{\mathrm{F}}\right)$ & $4 \mathrm{~m} / \mathrm{min}$ \\
Maximum Work-piece height & $200 \mathrm{~mm}$ & Pulse Current $\left(\mathrm{I}_{\mathrm{P}}\right)$ & $12 \mathrm{~A}$ \\
Maximum table size & $370^{*} 600 \mathrm{~mm}$ & Peak Voltage $\left(\mathrm{V}_{\mathrm{P}}\right)$ & $11 \mathrm{~V}$ \\
Maximum cutting speed & $70 \mathrm{~mm} / \mathrm{min}$ & Water Pressure $\left(\mathrm{W}_{\mathrm{P}}\right)$ & $1 \mathrm{~kg} / \mathrm{cm}^{2}$ \\
Taper & $\pm 8^{\circ}$ over $50 \mathrm{~mm}$ & Servo Voltage $\left(\mathrm{S}_{\mathrm{V}}\right)$ & $20 \mathrm{~V}$ \\
\hline
\end{tabular}

Table 3

Composition of the tool and work-piece material

\begin{tabular}{llll}
\hline Materials & Content & Tensile strength & Melting Point \\
\hline Brass & $\mathrm{Cu} \mathrm{65 \% ,} \mathrm{Zn} \mathrm{35 \%}$ & $45 \sim 60 \mathrm{kgf} / \mathrm{mm}^{2}$ & $900^{\circ} \mathrm{C}$ \\
Inconel 718 & $\mathrm{Ni}+\mathrm{Co} 50-55 \%, \mathrm{Cr} 17-21 \%$ & $800-1000 \mathrm{~N} / \mathrm{mm}^{2}$ & $1336^{\circ} \mathrm{C}$ \\
\hline
\end{tabular}

\subsection{Gear specifications and procedure}

The gear is obtained by taking the required pitch circle diameter, pressure angle and number of teeth's into consideration. The gear figure is obtained by using ELCAM software and the codes obtained were transferred to the wire EDM to machine the desired gear. Table 4 shows the gear values taken for the experiment. 
Table 4

Gear specifications used in the experimentation

\begin{tabular}{ll}
\hline Gear Specifications & Values \\
\hline Pressure angle & $20^{\circ}$ \\
Pitch circle diameter & $20 \mathrm{~mm}$ \\
Base diameter & $18.79 \mathrm{~mm}$ \\
Addendum diameter & $22.5 \mathrm{~mm}$ \\
Dedendum diameter & $16.87 \mathrm{~mm}$ \\
Tooth width & $1.96 \mathrm{~mm}$ \\
\hline
\end{tabular}

The present work deals with the cutting of work-piece material in the shape of a gear having 16 numbers of teeth. The thickness of the work-piece is $2 \mathrm{~mm}$ and the diameter of the wire is $0.25 \mathrm{~mm}$. The design is created using suitable software and 3 process parameters such as Pulse on time, Pulse off time and Wire tension were created by using Taguchi set of design with 16 numbers of combinations. The combinations obtained from the L16 orthogonal array design were being cut for each teeth with each set of combinations. The response parameters such as Material Removal Rate and Kerf width were measured after the completion of the machining operation. Fig. 1 shows the machining operation of the work-piece being cut by the wire EDM machine having 16 numbers of teeth.

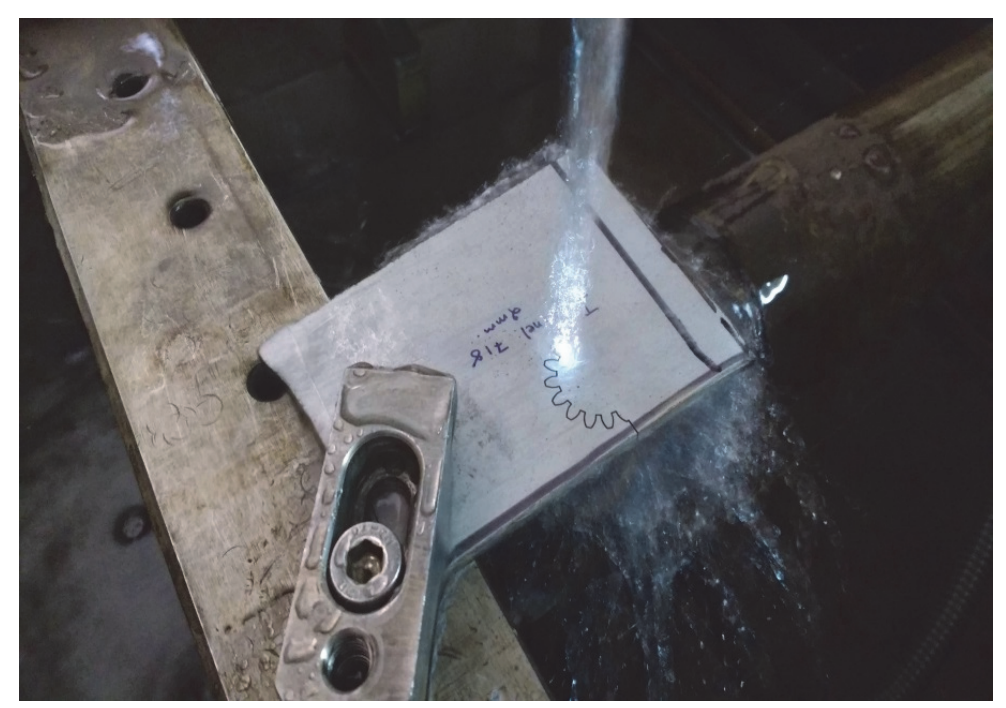

Fig. 1. Machining of the work-piece material by Wire EDM

\subsection{Determination of Material Removal Rate and Kerf width}

Material Removal Rate (MRR) is the volume of the metal detached from the material-piece during the cutting process. The volume of the material removed depends upon the cutting speed, thickness of the work-piece and diameter of the wire. The material is removed by the spark produced from the wire that The Material Removal Rate $\left(\mathrm{mm}^{3} / \mathrm{min}\right)$ is given by the following formulae:

$$
M R R=V_{c} \times h \times k
$$

where $\mathrm{Vc}$ is the cutting speed in $\mathrm{mm} / \mathrm{min}$, depends upon the cutting length and time.

The Cutting Speed $(\mathrm{Vc})$ is given by the following formulae:

$$
V_{c}=60 \times l / t
$$


where $l$ is the cutting length in mm and $t$ is the machining time in minutes. The Kerf width is the gap obtained in the work-piece after the machining operation. Generally the width is more than the wire diameter due to the sparks developed in the wire known as spark gap. The kerf width is generally measured in $\mathrm{mm}$. The Kerf obtained is viewed under the optical microscope by using suitable software. Fig. 2 shows the Kerf obtained after the machining operation observed under the optical microscope at 20X zoom.
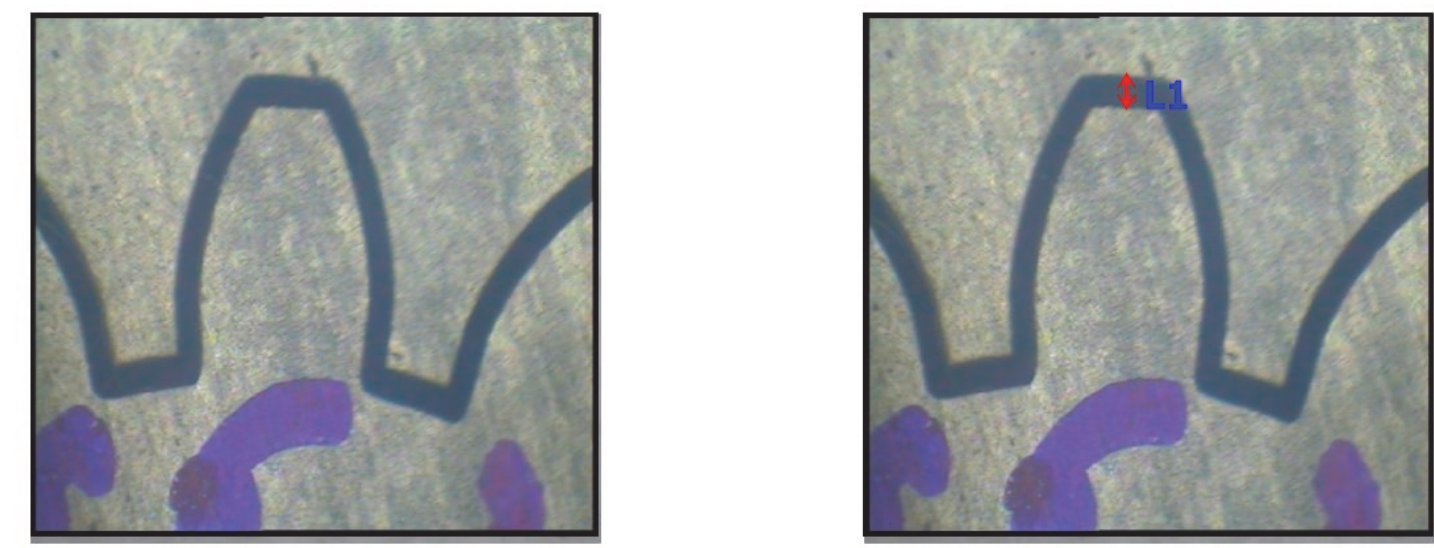

\begin{tabular}{c|c|c|c|l|l|l|l|l|}
\hline Measurement Name & Description & Results (Micron) & $\begin{array}{c}\text { Calibration } \\
\text { (Micron/Pixel) }\end{array}$ & & & & \\
\hline L1 & Length & 15.419 Micron & $\begin{array}{c}\text { X: } 100 / 264 \text { Y: } \\
100 / 264\end{array}$ & & & & & \\
\hline
\end{tabular}

Fig. 2. Work-piece observed under optical microscope at 20X zoom

\subsection{Design of the experiments using L16 array}

The experiment was conducted for 16 sets of combinations repeated once. The output responses such as Kerf width and Material Removal Rate have been obtained from the experiments. Table 5 shows the experimental design and work carried out using sixteen different sets of combinations.

Table 5

Design of experiments using L16 array

\begin{tabular}{llll|lll}
\hline SL No. & \multicolumn{3}{c|}{ Input Parameters } & \multicolumn{3}{c}{ Output Parameters } \\
\cline { 2 - 7 } & T $_{\text {ON }}$ & \multicolumn{1}{c|}{ T $_{\text {OFF }}$} & $\mathbf{W}_{\mathbf{T}}$ & $\mathbf{V}_{\mathbf{C}}$ & MRR & KW \\
\hline $\mathbf{1}$ & 110 & 50 & 4 & 2.95 & 1.476 & 0.640 \\
$\mathbf{2}$ & 110 & 53 & 5 & 2.83 & 1.416 & 0.707 \\
$\mathbf{3}$ & 110 & 55 & 6 & 2.60 & 1.3 & 0.687 \\
$\mathbf{4}$ & 110 & 57 & 7 & 2.65 & 1.325 & 0.626 \\
$\mathbf{5}$ & 113 & 50 & 5 & 3.22 & 1.61 & 0.747 \\
$\mathbf{6}$ & 113 & 53 & 4 & 3.34 & 1.67 & 0.707 \\
$\mathbf{7}$ & 113 & 55 & 7 & 3.31 & 1.655 & 0.687 \\
$\mathbf{8}$ & 113 & 57 & 6 & 3.30 & 1.65 & 0.687 \\
$\mathbf{9}$ & 116 & 50 & 6 & 3.21 & 1.605 & 0.707 \\
$\mathbf{1 0}$ & 116 & 53 & 7 & 3.35 & 1.675 & 0.666 \\
$\mathbf{1 1}$ & 116 & 55 & 4 & 3.69 & 1.845 & 0.707 \\
$\mathbf{1 2}$ & 116 & 57 & 5 & 3.62 & 1.81 & 0.666 \\
$\mathbf{1 3}$ & 119 & 50 & 7 & 3.22 & 1.61 & 0.707 \\
$\mathbf{1 4}$ & 119 & 53 & 6 & 3.25 & 1.625 & 0.631 \\
$\mathbf{1 5}$ & 119 & 55 & 5 & 3.39 & 1.695 & 0.606 \\
$\mathbf{1 6}$ & 119 & 57 & 4 & 3.47 & 1.735 & 0.602 \\
\hline
\end{tabular}


Fig. 3 depicts the gear obtained after the machining operation. Fig. 3(a) shows the gear obtained having 16 numbers of teeth. Fig 3(b) and 3(c) depicts the top and side surface of the gear respectively. It can be seen from the figure that the wire EDM machine gives accurate surface finish and accuracy after being machined by wire EDM. Fig 3(d) depicts the nomenclature of the gear showing its tooth width and face width of the gear teeth.
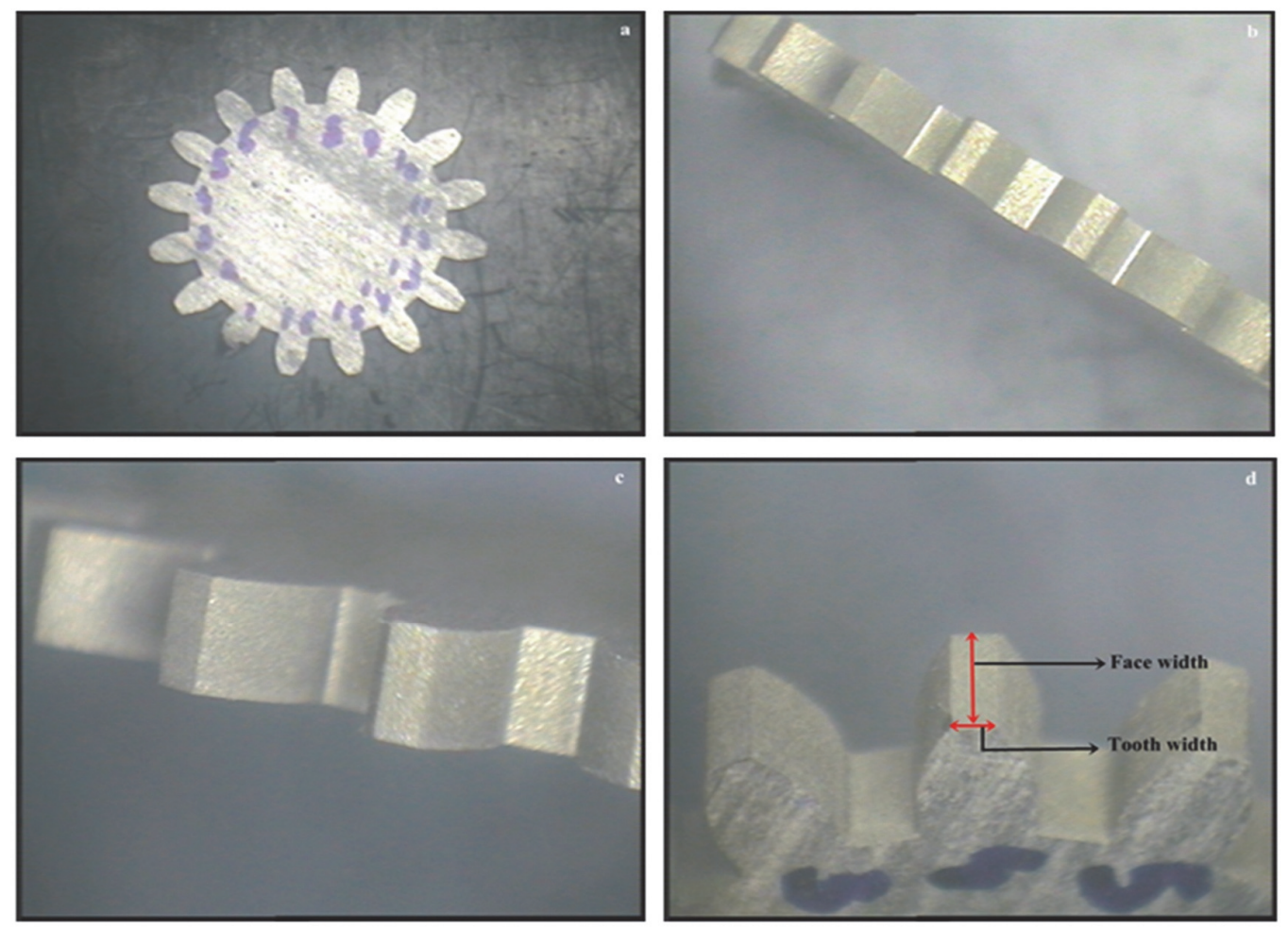

Fig. 3. Gears obtained after machining showing (a) 16 numbers of teeth, (b) top surface of the gear, (c) Side surface of the gear and (d) Nomenclature of the gear

\section{Optimization of the Response Parameters}

Optimization is a technique used to predict the best set from the given set of combinations. In order to get the optimized value, the MRR should be maximized and Kerf width should be minimized. A Multi objective optimization is used to combine both the responses in order to get a single value for the best possible outcome. The need for the optimization is to normalize the results and to get a best combination from the given sets.

The Technique for Order of Preference by Similarity to Ideal Solution (TOPSIS) is a technique by which the chosen alternatives have the shortest distance from the best solution and farthest from the negative ideal solution. A TOPSIS solution is the alternative which is closest to the ideal alternative and farthest from the negative ideal. The TOPSIS method consists of the following steps.

Step 1: The evaluation matrix is created with $\mathrm{n}$ criteria and $\mathrm{m}$ alternatives, intersecting each alternative and criteria as $x_{i j}$, therefore the matrix becomes $\left(x_{i j}\right)_{\mathrm{m} * \mathrm{n}}$.

Step 2: The matrix $\left(x_{i j}\right)_{\mathrm{m}^{*} \mathrm{n}}$. is then normalized to form the matrix

$$
R=\left(r_{i j}\right)_{\mathrm{m}^{*} \mathrm{n}} \text { using the normalization method }\left(r_{i j}\right)=\frac{x_{i j}}{\sqrt{\sum_{i=1}^{m} x_{i j}^{2}}}, \mathrm{i}=1,2, \ldots, \mathrm{m}, \mathrm{j}=1,2, \ldots, \mathrm{n}
$$

Step 3: Calculate the weight normalized values of the decision matrix as 


$$
T=\left(t_{i j}\right)_{\mathrm{m}^{* \mathrm{n}}}=\left(w_{j} r_{i j}\right)_{\mathrm{m}^{* \mathrm{n}}}, \mathrm{i}=1,2, \ldots, \mathrm{m}
$$

where $w_{j}$ is the weight of the $j$ th criterion set by the decision maker so that $\sum_{j=1}^{n} w_{j}=1$

Step 4: Identify the best alternative $\left(A_{B}\right)$ and the worst alternative $\left(A_{W}\right)$

$\mathrm{A}_{\mathrm{B}}=\left\{\left(\max (W \mid i=1,2, \ldots, m) \mid j \in j_{-}\right),\left(\min (W \mid i=1,2, \ldots, m) \mid j \in j_{+}\right)\right\}$

$\mathrm{A}_{\mathrm{W}}=\left\{\left(\min (W \mid i=1,2, \ldots, m) \mid j \in j_{-}\right),\left(\max (W \mid i=1,2, \ldots, m) \mid j \in j_{+}\right)\right\}$

where $j_{+}=(\mathrm{j}=1,2, \ldots, \mathrm{n} \mid \mathrm{j}$ associated with the criteria having maximization impact and $j_{-}=(\mathrm{j}=1,2, \ldots, \mathrm{n} \mid \mathrm{j}$ associated with the criteria having minimization impact.

Step 5: Calculate the Euclidean distance for each solution from the best and the worst alternative.

$$
\begin{aligned}
& d_{i w}=\sqrt{\sum_{j=1}^{n}\left(t_{i j}-t_{w j}\right)^{2}}, i=1,2, \ldots, m \\
& d_{i b}=\sqrt{\sum_{j=1}^{n}\left(t_{i j}-t_{b j}\right)^{2}}, i=1,2, \ldots, m
\end{aligned}
$$

where, $d_{i w}$ and $d_{i b}$ are the distances from the target alternative $\mathrm{i}$ to the worst and the best conditions respectively.

Step 6: Calculate the Relative Closeness Coefficient $\left(s_{i w}\right)$ to the ideal solution

$$
\begin{aligned}
& s_{i w}=\frac{d_{i w}}{d_{i w}+d_{i b}}, 0 \leq s_{i w} \leq 1, \mathrm{i}=1,2, . ., \mathrm{m} \\
& s_{i w}=1, \text { if and only if the alternative solution is the best solution } \\
& s_{i w}=0, \text { if and only if the alternative has the worst condition }
\end{aligned}
$$

Step 7: Rank the alternatives according to $s_{i w}(\mathrm{i}=1,2, \ldots, \mathrm{m})$

\begin{tabular}{|c|c|c|c|c|c|}
\hline Run & MRR & Kerf & $d_{i w}$ & $d_{i b}$ & $s_{i w}$ \\
\hline 1 & 1.476 & 0.640 & 0.037 & 0.0241 & 0.3890 \\
\hline 2 & 1.416 & 0.707 & 0.0379 & 0.0119 & 0.2400 \\
\hline 3 & 1.3 & 0.687 & 0.0443 & 0.0107 & 0.1951 \\
\hline 4 & 1.325 & 0.626 & 0.0396 & 0.0221 & 0.3588 \\
\hline 5 & 1.61 & 0.747 & 0.0323 & 0.0247 & 0.4333 \\
\hline 6 & 1.67 & 0.707 & 0.0236 & 0.0302 & 0.5613 \\
\hline 7 & 1.655 & 0.687 & 0.0213 & 0.0302 & 0.5863 \\
\hline 8 & 1.65 & 0.687 & 0.0215 & 0.0298 & 0.5805 \\
\hline 9 & 1.605 & 0.707 & 0.0266 & 0.0253 & 0.4875 \\
\hline 10 & 1.675 & 0.666 & 0.0173 & 0.0331 & 0.6561 \\
\hline 11 & 1.845 & 0.707 & 0.01999 & 0.0435 & 0.6852 \\
\hline 12 & 1.81 & 0.666 & 0.0125 & 0.0428 & 0.7739 \\
\hline 13 & 1.61 & 0.707 & 0.0263 & 0.0257 & 0.4936 \\
\hline 14 & 1.625 & 0.631 & 0.0171 & 0.0334 & 0.6610 \\
\hline 15 & 1.695 & 0.606 & 0.0107 & 0.0405 & 0.7905 \\
\hline 16 & 1.735 & 0.602 & 0.00758 & 0.0434 & 0.8513 \\
\hline
\end{tabular}

Table 6 shows the multi-objective optimization of the output parameters using TOPSIS method. From the Table it is seen that the highest alternative is in the $16^{\text {th }}$ run (119-57-4), which is the best alternative among the given set of combinations.

\section{Table 6}

Multi-objective Optimization using TOPSIS method 


\section{Analysis of the Experimental Data}

\subsection{Microstructural analysis of the material and the wire}

The experiment was conducted and it was found that the optimum setting occurs at Pulse on time 119 $\mu \mathrm{s}$, Pulse off time $57 \mu \mathrm{s}$ and $\mathrm{W}_{\mathrm{T}} 4 \mathrm{~kg}$-f. This combination was found to be optimum among the sixteen combinations and all the analysis was carried out at the optimum settings. This setting confirms that the gear gives a better cutting accuracy with maximum Material Removal and minimum Kerf. Fig. 4 shows the SEM image of the brass wire after the machining operation. From the Fig. 4(a), it is seen that there are some cut marks in the wire which indicates the direction of travel of the wire. The wire also undergoes some wear after the machining operation due to the sparks produced in the wire. Fig. 4(b) depicts that there are some craters produced and spherical droplets formed on the wire. High discharge energy at constant voltage and current are the occurrence of such craters and spherical droplets formed on the wire. Fig. 4(c) shows that there are some burrs and voids produced in the wire. The sparks generated from the wire at high cutting speed results in the formation of voids and removal of wear from the wire in the form of burrs.
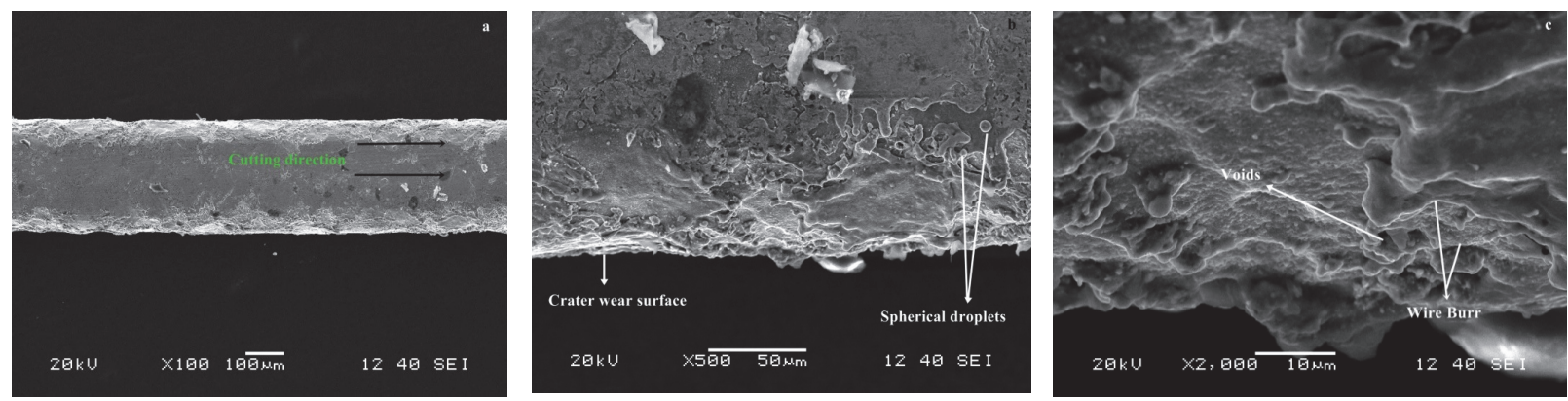

Fig. 4. Micrographs of the wire $\left(\mathrm{T}_{\mathrm{ON}} 119, \mathrm{~T}_{\mathrm{OFF}} 57, \mathrm{~W}_{\mathrm{T}} 4\right)$ after machining (a) at $100 \mathrm{X}(\mathrm{b})$ at $500 \mathrm{X}$ and (c) at $2000 \mathrm{X}$
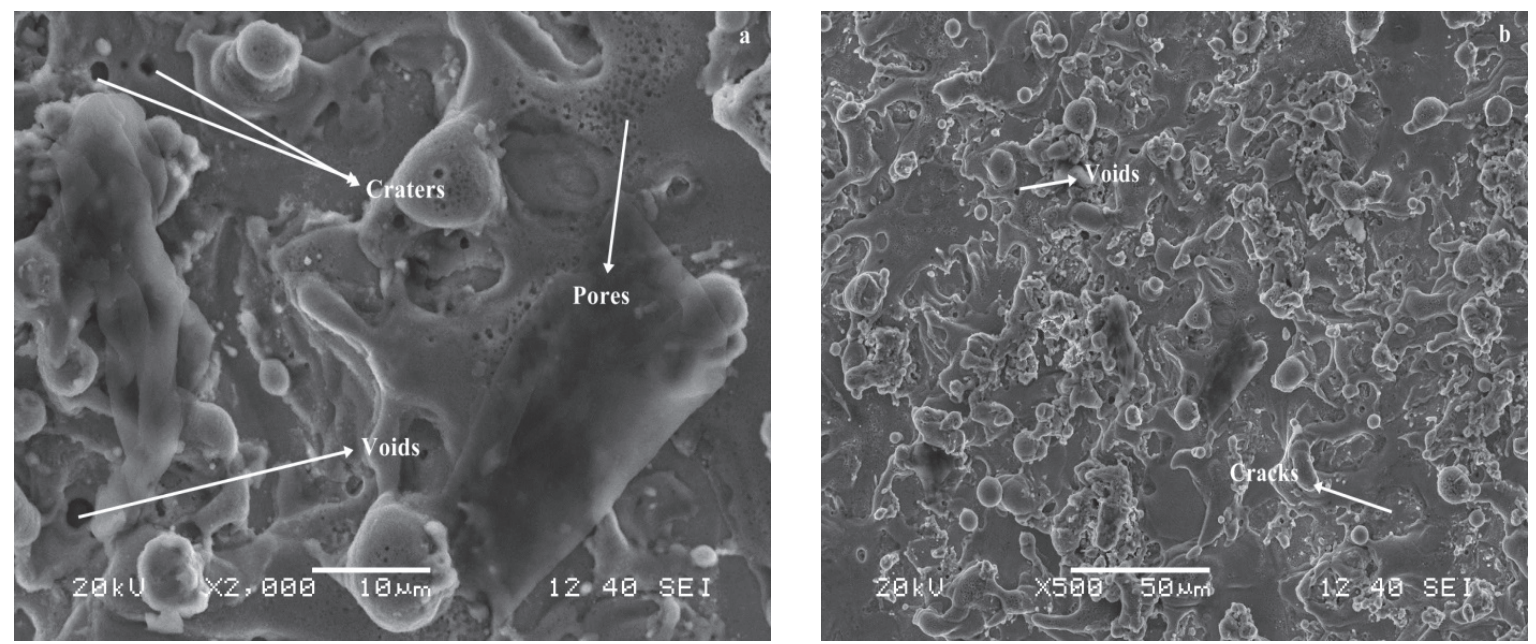

Fig. 5. Micrographs of the material ( $\left.\mathrm{T}_{\mathrm{ON}} 119, \mathrm{~T}_{\mathrm{OFF}} 57, \mathrm{~W}_{\mathrm{T}} 4\right)$ after machining (a) at $2000 \mathrm{X}$ (b) at $500 \mathrm{X}$

Fig. 5 shows the micrographs of the material after machining operation at $\mathrm{T}_{\mathrm{ON}} 119 \mu \mathrm{s}, \mathrm{T}_{\mathrm{OFF}} 57 \mu \mathrm{s}, \mathrm{W}_{\mathrm{T}}$ $4 \mathrm{~kg}$-f. The image is taken at the surface near to the cutting edge of the material. The sparks produced from the wire removes the work-piece material and gets flushed by the dielectric. There are some heat affected zones produced in the material as well as there are some chances of formation of recast layer. From the figure it can be seen that the material undergoes voids, craters and pores. The formation of 
voids and craters is due to the increase in the wire feed rate which increases the cutting speed of the wire with high spark energy density resulting in the formation of craters, pores and voids on the material surface.

\section{Results and Discussion}

\subsection{Effects of Process parameters on Relative Closeness Coefficient (RCC)}

Fig. 6 shows the main effect plot diagram for RCC against Pulse on time, Pulse off time and Wire Tension. The effects can be observed from the graphs. From Fig. 6(a) and Fig. 6(b) it can be seen that the RCC increases with the increase in the Pulse on time and Pulse off time. The increase in the cutting speed due to high spark energy density results in high values of RCC. Moreover more discharge energy is drawn from the plasma channel resulting in the increase in the sparking efficiency resulting in high values of RCC. Fig. 6(c) depicts that with the increase in the wire tension RCC decreases, then increases. With the increase in the wire tension and Pulse off time, the cutting speed decreases. High induced reaction forces and water pressure are the reasons for the decrease in the RCC. After a certain point the wire tension increases. This is due to the fact that the geometry accuracy of the work piece is being influenced by wire vibration in machining of thin work-piece causing the wire to be straighter resulting in an increase in the spark.
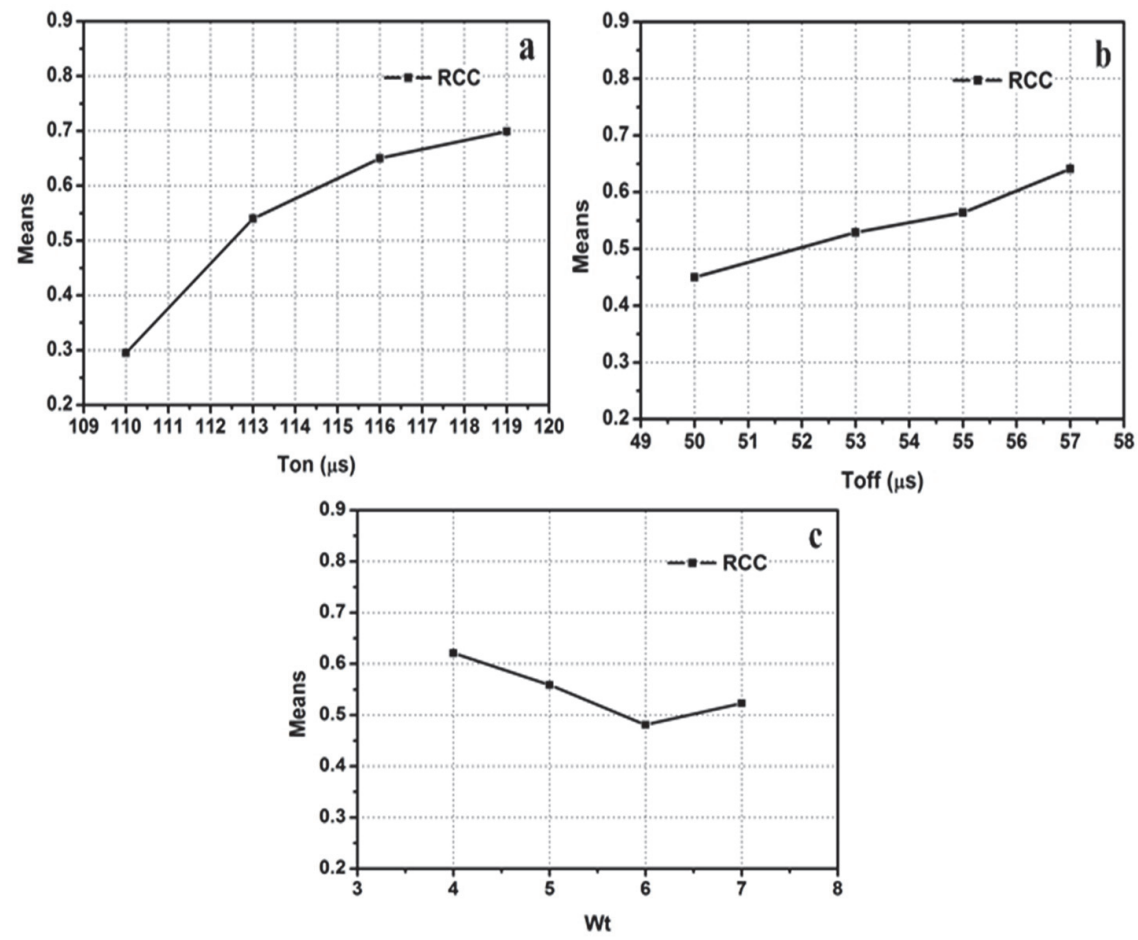

Fig. 6. Main effect plot diagram for RCC and (a) Pulse on time (b) Pulse off time and (c) Wire Tension

\subsection{Statistical models for MRR and $K W$}

The Regression equations were obtained by using suitable software by selecting the process and response parameters of the model. Fig. 7 shows the comparison between statistical and experimental models for MRR and KW.

The suggested regression equation for MRR and KW are 
$M R R=-2.22+0.0316 T_{O N}+0.0083 T_{O F F}-0.0433 W_{T}$

$K W=1.46-0.00353 T_{O N}-0.00738 T_{\text {OFF }}+0.00190 W_{T}$

Regression coefficients, $\left(\mathrm{R}^{2}\right) 0.92$ and 0.90 in MRR and KW respectively indicate a good sign of predicted values with the experimental.
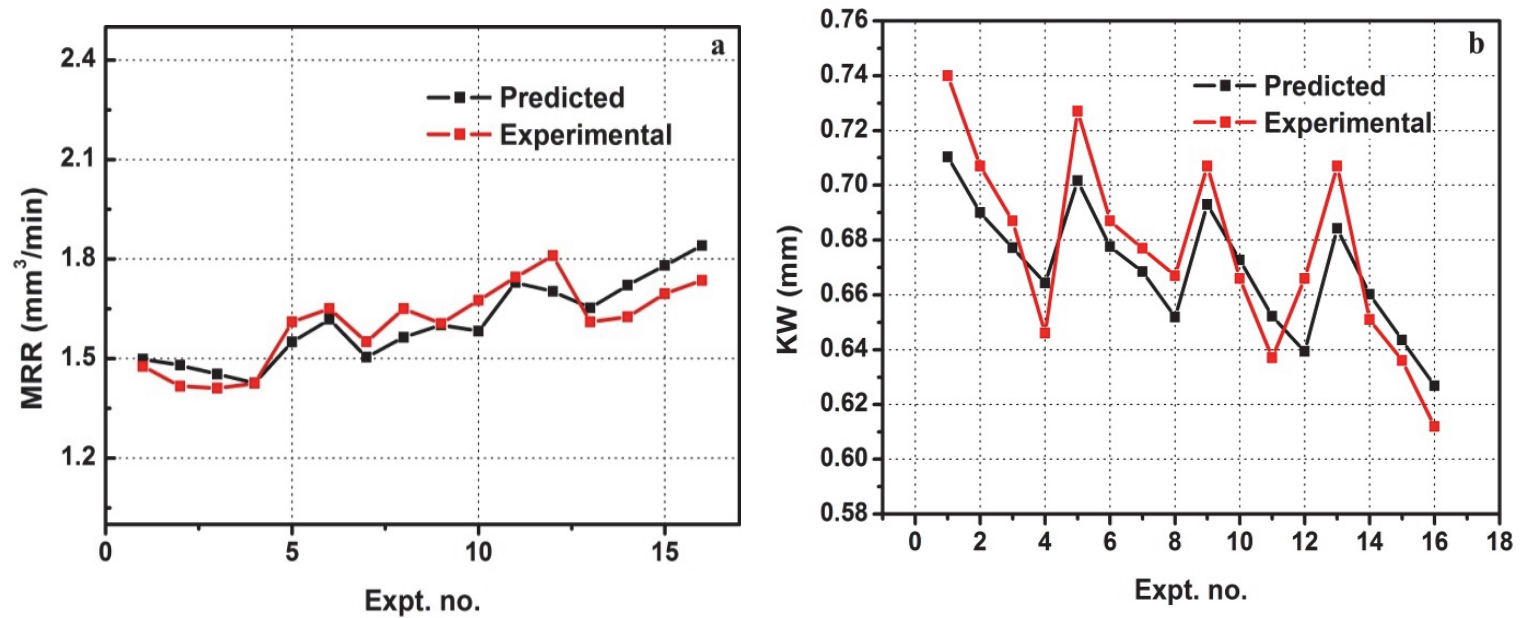

Fig. 7. Comparison between predicted and experimental model for (a) MRR (b) KW

Table 7 shows the analysis of the statistical models for MRR and KW. A R $\mathrm{R}^{2}$ value of $92.1 \%$ and $\mathrm{R}^{2}$ (adj) of $89.2 \%$ predicts a good sign of regression model for MRR. Similarly a $R^{2}$ value of $90.7 \%$ and $\mathrm{R}^{2}$ (adj) of $88.6 \%$ depicts a good sign of regression model for KW.

\section{Table 7}

Analysis of the statistical models for MRR and KW

\begin{tabular}{lllllllll}
\hline Predictor & \multicolumn{4}{c}{ MRR } & \multicolumn{4}{c}{ KW } \\
\cline { 2 - 9 } & Coef & SE Coef & T & P & Coef & SE Coef & T & P \\
\hline Constant & -2.223 & 1.078 & -2.06 & 0.062 & 1.4647 & 0.3940 & 3.72 & 0.003 \\
T $_{\text {ON }}$ & 0.0316 & 0.00798 & 3.96 & 0.002 & -0.0035 & 0.0029 & -1.21 & 0.249 \\
T $_{\text {OFF }}$ & 0.0083 & 0.01035 & 0.80 & 0.437 & -0.0073 & 0.0037 & -1.95 & 0.075 \\
$\mathbf{W}_{\text {T }}$ & -0.0433 & 0.0239 & -1.81 & 0.095 & 0.0019 & 0.0087 & 0.22 & 0.832 \\
\hline
\end{tabular}

\subsection{ANOVA for Relative Closeness Coefficient}

Analysis of Variance or ANOVA is a tool which tells which process parameter significantly affects the responses. In other words, the factor is said to be significant if the Probability (P) value is less than 0.05. Table 8 shows the ANOVA table for RCC. From the table it is seen that Pulse on time is the most significant factor (0.002) affecting the responses. However Pulse off time and Wire Tension has also effects in affecting the responses but optimizing the response parameters, Pulse off time and Wire Tension are the least significant factors than Pulse on time.

Table 8

Analysis of Variance for RCC

\begin{tabular}{lllllll}
\hline Source & DF & Seq SS & Adj SS & Adj MS & F & P \\
\hline $\mathbf{T}_{\text {on }}$ & 3 & 0.388 & 0.388 & 0.129 & 18.30 & 0.002 \\
$\mathbf{T}_{\text {off }}$ & 3 & 0.0748 & 0.0748 & 0.024 & 3.53 & 0.088 \\
$\mathbf{W}_{\mathbf{T}}$ & 3 & 0.0425 & 0.0425 & 0.0141 & 2.00 & 0.215 \\
Residual Error & 6 & 0.0424 & 0.0424 & 0.0070 & & \\
\hline Total & 15 & 0.54808 & & & & \\
\hline
\end{tabular}




\subsection{Response table for Relative Closeness Coefficient}

Response table determines the rank of the process parameters. From the Table 9 it is seen that Pulse on time is the most affecting parameter followed by Pulse off time and Wire tension in multi objective optimization of response parameters.

\section{Table 9}

Response table for RCC

\begin{tabular}{llll}
\hline Level & $\mathbf{T}_{\text {on }}$ & $\mathbf{T}_{\text {off }}$ & $\mathbf{W}_{\mathbf{T}}$ \\
\hline $\mathbf{1}$ & 0.2958 & 0.4509 & 0.6217 \\
$\mathbf{2}$ & 0.5404 & 0.5296 & 0.5595 \\
$\mathbf{3}$ & 0.6507 & 0.5643 & 0.4811 \\
$\mathbf{4}$ & 0.6691 & 0.6412 & 0.5237 \\
Delta & 0.4034 & 0.1903 & 0.1407 \\
Rank & 1 & 2 & 3 \\
\hline
\end{tabular}

\subsection{Analysis of various Plots}

The Normal Probability plot is a graphical technique which indicates that whether the experimental data's are normally distributed or not. Fig. 8 shows the Residual plot or Normal Probability plot obtained after the experiment. The points more close to the line indicates the best results. From the figure it is seen that all the 16 sets of experiments carried out were close to the normal line which satisfies the fitness of the experiment.

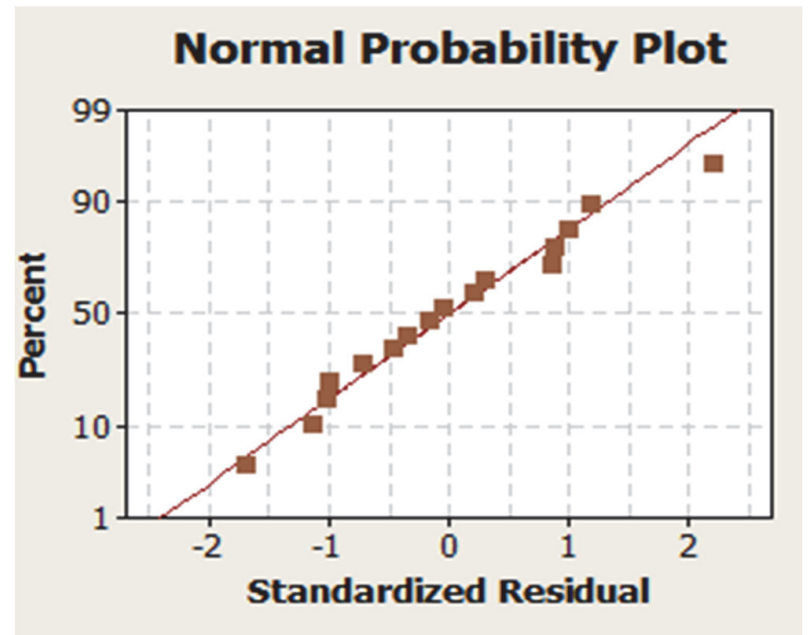

Fig. 8. Normal Probability plot obtained from the experiment

Contour plots and surface plots are often used to determine the potential relationship between three variables. They are used to establish response values and operating conditions according to the users. The darker region indicates high response values. Fig. 9 shows the contour plot of RCC with Pulse on time and Pulse off time. The contour plot reveals that RCC is highest in the region of $\mathrm{T}_{\mathrm{OFF}} 57 \mu$ s and $\mathrm{T}_{\mathrm{ON}} 119 \mu$ s and lowest in the region of $\mathrm{T}_{\mathrm{ON}} 113 \mu \mathrm{s}$ and $\mathrm{T}_{\mathrm{OFF}} 53 \mu \mathrm{s}$. Similarly the surface plot from fig. 10 reveals that $\mathrm{RCC}$ is highest is the region of $\mathrm{T}_{\mathrm{OFF}} 54 \mu \mathrm{s}$ and $\mathrm{T}_{\mathrm{ON}} 110 \mu \mathrm{s}$ and lowest in the region of $\mathrm{T}_{\mathrm{ON}} 116 \mu \mathrm{s}$ and $\mathrm{T}_{\mathrm{OFF}} 57 \mu \mathrm{s}$. 


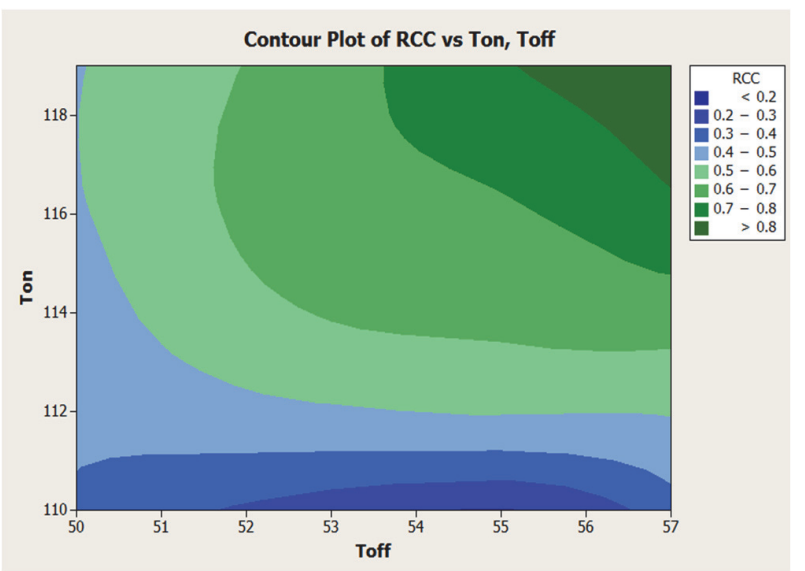

Fig. 9 Contour plot of RCC and Pulse on time and Pulse off time

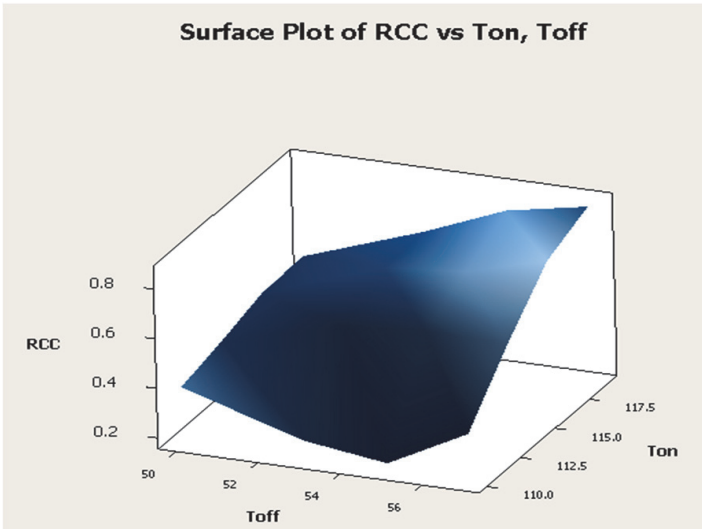

Fig. 10. Surface plot of RCC and Pulse on time and Pulse off time

\subsection{Measurement of Surface roughness, Addendum and Tooth width at optimum settings}

Apart from Kerf and Material Removal, accuracy and machined surface quality like surface roughness, surface finish plays a significant role in determining the output responses in wire EDM process. Wire EDM is capable of providing excellent surface finish similar to that of the grinding wheel. The volume of the material removed depends on the desired cutting speed and the surface finish required. Surface Roughness $\left(R_{a}\right)$ is measured by an instrument called Talysurf. The Addendum, Tooth width and the Surface roughness was measured for the teeth $\left(16^{\text {th }}\right)$ at the optimum settings. Fig. 11 depicts the gear parameters such as Addendum and Tooth width at the optimum settings. Fig. 12 shows the measurement of the Tooth width and Addendum at the optimum setting of $20 \mathrm{X}$ optical zoom.

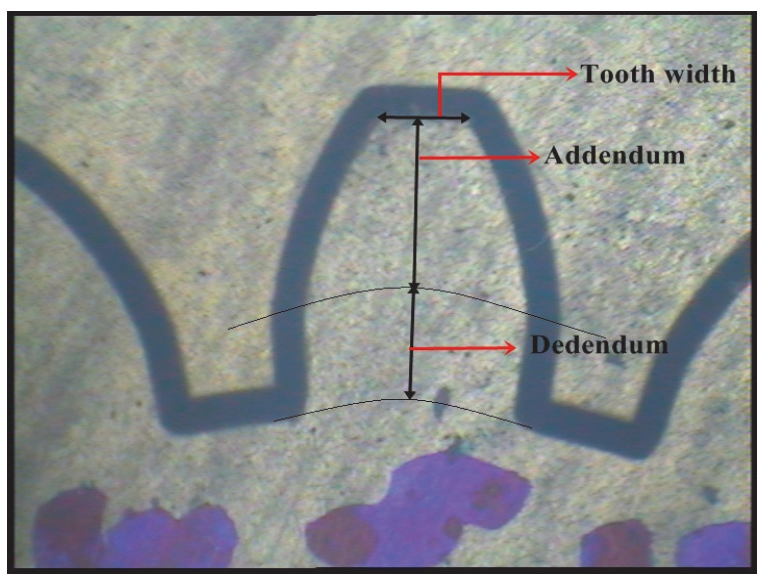

Fig. 11. Nomenclature of the gear parameters showing Tooth width, Addendum and Dedendum

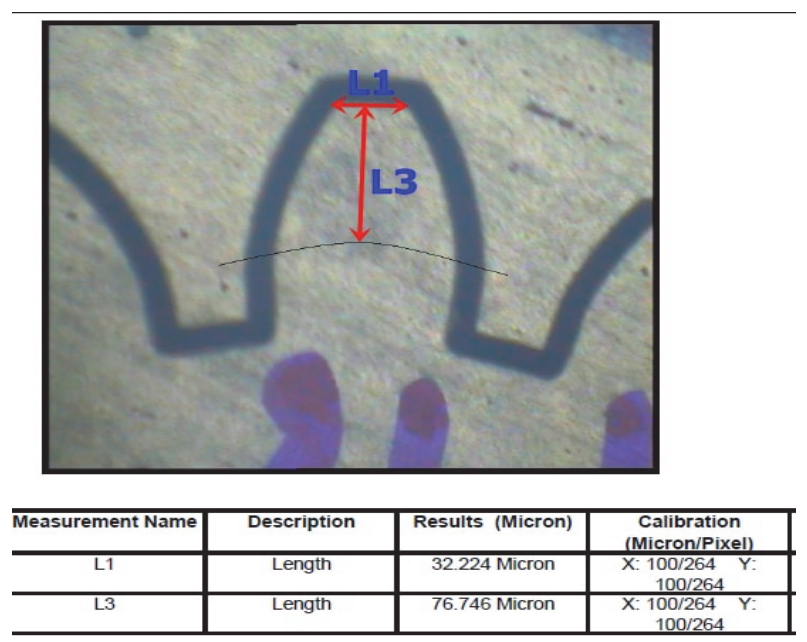

Fig. 12. Measurement of the Tooth width and Addendum at an optimum setting of $20 \mathrm{X}$ zoom

Table 10

Measurement of Surface roughness, Addendum and Tooth width at optimum setting

\begin{tabular}{|c|c|c|c|}
\hline Optimum setting & $\begin{array}{l}\text { Surface } \\
\text { Roughness } \\
(\mu \mathrm{m})\end{array}$ & Addendum (mm) & Tooth Width (mm) \\
\hline $\begin{array}{l}\mathrm{T}_{\mathrm{ON}} 119 \mu \mathrm{s} \mathrm{T}_{\mathrm{OFF}} \\
57 \mu \mathrm{s} \mathrm{W}_{\mathrm{T}} 4 \mathrm{~kg}-\mathrm{f}\end{array}$ & 1.9 & 2.63 & $\begin{array}{ll}\text { Theoretical } & \text { Experimental } \\
1.96 & 1.108\end{array}$ \\
\hline
\end{tabular}


Table 10 shows the measurement of Surface roughness, Addendum and Tooth width at optimum settings. From the Table 10 it is seen that the surface roughness at the optimum setting was found to be $1.9 \mu \mathrm{m}$ confirming that the wire EDM is capable of producing excellent surface finish at optimum setting. Similarly the Addendum was found to be $2.63 \mathrm{~mm}$ and the Tooth thickness was found to be $1.108 \mathrm{~mm}$. An error or $0.852 \mathrm{~mm}$ in tooth thickness predicts a good sign of machining at the optimum setting.

\section{Conclusions}

The following paper presented an experimental analysis and optimization of parameters in a gear cutting process by Wire EDM. Following conclusions were made based on the results and experimental work carried out. The gear is obtained by minimizing the kerf width and maximizing the material removal rate. Pulse on time is found to be the most significant factor in affecting the responses. The MRR and kerf was measured and optimized using TOPSIS method. The microstructural analysis was carried out for material and the wire. It was found that some craters, voids and pores are formed on the work-piece as well as the wire due to change in the wire feed rate at high Pulse on time. The main effect plot shows that the Relative closeness coefficient increases with the increase in Pulse on time and Pulse off time due to different spark energy density and decreases with the increase in Wire tension due to reaction forces and high water pressure. Statistical model was also analysed and the equations of regressions were found out and validated with the experimental. Regression coefficients, $\left(R^{2}\right) 0.92$ and 0.90 in MRR and KW respectively indicate a good sign of predicted values with the experimental. The Normal Probability plot was obtained showing all the points close to the normal line satisfying the fitness of the experiment. The contour plot reveals that RCC is highest in the region of $\mathrm{T}_{\text {OFF }} 57 \mu$ s and $\mathrm{T}_{\mathrm{ON}} 119 \mu \mathrm{s}$ and lowest in the region of $\mathrm{T}_{\mathrm{ON}} 113 \mu \mathrm{s}$ and $\mathrm{T}_{\mathrm{OFF}} 53 \mu \mathrm{s}$. Similarly the surface plot reveals that $\mathrm{RCC}$ is highest is the region of $\mathrm{T}_{\mathrm{OFF}} 54 \mu \mathrm{s}$ and $\mathrm{T}_{\mathrm{ON}} 110 \mu \mathrm{s}$ and lowest in the region of $\mathrm{T}_{\mathrm{ON}} 116 \mu \mathrm{s}$ and $\mathrm{T}_{\mathrm{OFF}} 57 \mu \mathrm{s}$. The Surface roughness, Addendum and Tooth width were also experimented and analysed at the optimum settings. The addendum was found to be $2.63 \mathrm{~mm}$. It was also found that the tooth width has an error of $0.852 \mathrm{~mm}$ satisfying the validation at the optimum settings. From the above analysis, it was clear that the optimum setting of the gear obtained can be used to produce high quality gears and can also be applied for future findings.

\section{References}

Banerjee, S., Prasad, B. V. S. S. S., \& Mishra, P.K. (1993). A simple model to estimate the thermal loads on an EDM wire electrode. Journal of Material Processing Technology, 39(3-4), 305-317.

Geng, X., Chi, G., Wang, Y., \& Wang, Z. (2014). Study on Microrotating Structure Using Microwire Electrical Discharge Machining. Materials and Manufucturing Processes, 29(3), 274-280.

Habib, S., \& Okada, A. (2016). Journal of Materials Processing Technology Study on the movement of wire electrode during fine wire electrical discharge machining process. Journal of Material Processing Technology, 227, 147-152.

Kumar, A., Kumar, V., Kumar, J., \& Markandeshwar, M. (2014). A microstructure analysis and material transformation of pure titanium and tool wear surface after wire electric discharge. Machining Science and Technology, 18(1), 47-77.

Li, L., Li, Z.Y., Wei, X.T., \& Cheng, X. (2014). Machining Characteristics of Inconel 718 by SinkingEDM and Wire-EDM. Materials and Manufacturing Processes, 30(8), 968-973.

Mohapatra, K.D., \& Sahoo, S.K. (2015). Micro-Structural Analysis and Multi-Objective Optimization in Gear Cutting Process for Aisi 304 Stainless Steel Using Wire EDM. International Journal of Mechanical and Production Engineering, 3(6), 109-114.

Mohapatra, K.D., \& Sahoo, S.K. (2015). Experimental Investigation of Wire Edm Parameters for Gear Cutting Process Using Desirability With PCA. International Journal for Technological Research in Engineering, 2(10), 2415-2419.

Mohapatra, K.D., \& Sahoo, S.K. (2014). Parametric optimization of wire EDM process for gear cutting. 
Journal of Basic and Applied Engineering Research, 1(3), 78-84.

Rajurkar, K. P., \& Wang, W. M. (1993). Thermal modeling and on-line monitoring of wireEDM. Journal of Materials Processing Technology, 38(1-2), 417-430.

Spedding, T., \& Wang, Z. (1997). Study on modeling of wire EDM process. Journal of Material Processing Technology, 69(1-3), 18-28.

Sharma, P., Chakradhar, D., \& Narendranath, S. (2016). Effect of wire diameter on surface integrity of wire electrical discharge machined Inconel 706 for gas turbine application. Journal of Manufacturing Processes, 24, 170-178.

Singh, H., \& Garg, G. (2009). Effects of process parameters on material removal rate in WEDM. Journal of Achievements in Materials and Manufucturing Engineering, 32(1), 70-74.

Subhramanyam, S.V., \& Sarcar, M.M.M. (2013). Statisitical analysis of Wire Electric Discharge Machining on Surface Finish. International Journal of Engineering Research and Technology, 2(3), $1-8$.

Taylor, P., Mandal, A., Dixit, A.R., Das, A.K., \& Mandal, N. (2015). Materials and Manufacturing Processes Modeling and Optimization of Machining Nimonic C-263 Super Alloy Using Multi-Cut Strategy in WEDM. Materials and Manufacturing Processes, 31(7), 860-868.

Zhang, G., Chen, Z., Zhang, Z., Huang, Y., Ming, W., \& Li, H. (2014). A macroscopic mechanical model of wire electrode deflection considering temperature increment in MS-WEDM process. International Journal of Machine Tools and Manufacture, 78, 41-53.

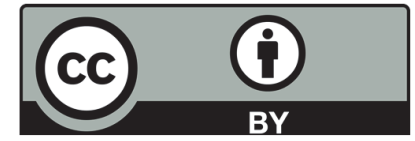

(C) 2017 by the authors; licensee Growing Science, Canada. This is an open access article distributed under the terms and conditions of the Creative Commons Attribution (CC-BY) license (http://creativecommons.org/licenses/by/4.0/). 